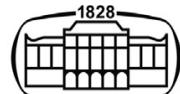

AKADÉMIAI KIADÓ

\section{Acta Veterinaria Hungarica}

$68(2020) 3,236-241$

Dol:

$10.1556 / 004.2020 .00040$ (c) 2020 The Author(s)

\section{RESEARCH ARTICLE}

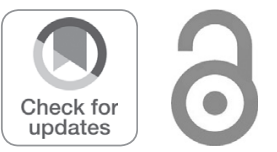

\title{
Occurrence and characterisation of methicillin- resistant Staphylococcus aureus isolated from bovine milk in Hungary
}

\author{
ERVIN ALBERT ${ }^{1 *}$, RITA SIPOS ${ }^{2}$, SZILÁRD JÁNOSI ${ }^{3}$, \\ PÉTER KOVÁCS ${ }^{4}$, ÁRPÁD KENÉZ ${ }^{5}$, ADRIENN MICSINAI ${ }^{2}$, \\ ZSÓFIA NOSZÁLY ${ }^{1}$ and IMRE BIKSI ${ }^{1}$ \\ ${ }^{1}$ Department of Pathology, University of Veterinary Medicine Budapest, Üllő, Dóra major, H-2225, \\ Hungary \\ 2 BIOMI Ltd., Gödöllő, Hungary \\ ${ }^{3}$ National Food Chain Safety Office, Veterinary Diagnostic Directorate, Budapest, Hungary \\ ${ }^{4}$ Department of Animal Hygiene, Herd Health and Mobile Clinic, University of Veterinary Medicine \\ Budapest, Budapest, Hungary \\ ${ }^{5}$ Livestock Performance Testing Ltd., Gödöllő, Hungary
}

Received: May 14, 2020 - Accepted: August 12, 2020

Published online: November 12, 2020

\begin{abstract}
The last surveys on methicillin-resistant Staphylococcus aureus (MRSA) isolated from bovine milk in Hungary took place in the 2000s. To elucidate the genetic variability and to estimate the burden of the pathogen, MRSA from our strain collection and prospectively collected Staphylococcus aureus (SA) isolates originating from two milk hygiene laboratories were investigated. Between 2003 and 2018, 27 MRSA strains originating from 10 dairy farms were deposited and characterised. Most strains $(n=20)$ belonged to ST1-t127-SCC mec IV and were recovered from three unrelated farms. From other farms, variable genotypes were identified sporadically: ST22-t032-SCC mec $\mathrm{IV}$ from three farms; a newly described double locus variant of ST97, ST5982-t458-SCC ${ }_{m e c}$ IV from two farms; and ST398-t011$\mathrm{SCC}_{m e c} \mathrm{IV}$ and ST398-t011-SCC $\mathrm{mec}_{\mathrm{V}} \mathrm{V}$ from two respective farms. The prospective screening of 626 individual SA isolates originating from 42 dairy farms resulted in four $(0.48 \%)$ MRSA strains from three $(7.14 \%)$ farms. All MRSA isolates belonged to the clonal complex 398 and a novel spa-type t19251 was also identified. Most isolates were resistant to three or more antimicrobial classes. The occurrence and significance of MRSA of dairy origin seems to be unchanged in the past decade in Hungary. However, the low host specificity and multiresistance of the identified genotypes calls for periodic revision on the role and distribution of the pathogen in the Hungarian dairy sector.
\end{abstract}

\section{KEYWORDS}

methicillin-resistant Staphylococcus aureus, dairy, genetic variability, resistance

\section{INTRODUCTION}

The first livestock-associated methicillin-resistant Staphylococcus aureus (LA-MRSA) case was published in 1972, although MRSA has been recognised as a rapidly emerging issue in livestock since the 2000s (Devriese et al., 1972; Fitzgerald, 2012). Depending on the genotype, LA-MRSA may colonise humans, especially those in occupational contact with farm animals. Human infections and cases of human-to-human transmission are reported to be rare (Cuny et al., 2015). In Europe, the swine industry is proven to be the primary source of LA-MRSA contamination (European Food Safety Authority, 2009), while the role of other host species seems to be less significant (Fitzgerald, 2012), including those from the dairy sector (Ou et al., 2017). In Hungary, the last surveys on the matter were conducted in the 2000s. Kaszanyitzky et al. (2004) 
investigated more than 2,000 S. aureus (SA) isolates of livestock origin and detected only five MRSA strains, which were all from dairy samples. Subsequently, the transmission of MRSA between cows and humans was also confirmed on one of the two affected dairy farms (Juhász-Kaszanyitzky et al., 2007). In 2006, Peles et al. (2007) could not isolate any MRSA from bulk tank milk samples of 20 dairy farms. In the subsequent decade, variable prevalence rates and numerous genotypes of dairyrelated LA-MRSA were reported from other European countries, while no survey was conducted in Hungary (Tenhagen et al., 2014; van Duijkeren et al., 2014; Cortimiglia et al., 2016; Parisi et al., 2016).

\section{MATERIALS AND METHODS}

\section{Origin of isolates}

To investigate the genetic variability of MRSA isolates from milk from the past 15 years, conserved MRSA strains of the Veterinary Diagnostic Directorate (VDD), National Food Chain Safety Office, Budapest were characterised further. Presumptive SA isolates from two large-scale milk hygiene laboratories [University of Veterinary Medicine Budapest (UVMB), Hungary and Livestock Performance Testing Ltd., Gödöllö, Hungary (LPT Ltd.)] were collected prospectively between July 2017 and December 2018.

\section{Molecular identification and genotyping of isolates}

All prospectively collected, presumptive SA strains were tested by multiplex polymerase chain reaction (PCR) for the presence of the SA-specific staphylococcus protein A gene $(s p a)$, the two variants of the methicillin-resistance coding genes, $m e c A$ and $m e c C$ (formerly $m e c A_{\mathrm{LGA} 251}$ ), as well as $p v l$ as a marker of the human-related virulence gene PantonValentine leukocidin (PVL; Stegger et al., 2012). Conserved MRSA strains from the VDD were tested in the same way. Genetic characterisation of all MRSA strains included spatyping and typing of the staphylococcus cassette chromosome carrying the methicillin resistance coding region (SCC $_{\text {mec }}$; Harmsen et al., 2003; Kondo et al., 2007). Multilocus sequence typing (MLST) was carried out on selected representative strains of each spa-type (Enright et al., 2000). MLST sequence types and spa-types were analysed using the corresponding plugin of the BioNumerics software (Applied Maths, BioMérieux, France).

\section{Antimicrobial susceptibility testing and resistance genes}

Antimicrobial susceptibility testing (AST) was performed on representative MRSA spa-types from each farm $(n=14)$ using the agar disc diffusion method and evaluated according to the standards of the European Committee on Antimicrobial Susceptibility Testing (EUCAST) for SA (Matuschek et al., 2014; European Committee on Antimicrobial Susceptibility Testing, 2019). In the case of streptomycin and tiamulin, there were no zone diameters available that were approved by EUCAST or Clinical Laboratory
Standard Institute (CLSI) standards. Besides phenotypic testing, streptomycin resistance was further evaluated for the presence of a resistance mechanism by investigating aadE and str genes in the 14 selected isolates (Klare et al., 2007; Schijffelen et al., 2010). Both genes are known to confer resistance towards streptomycin in staphylococci (Wendlandt et al., 2013). In the case of tiamulin, previously implemented and published zone diameters were used (Jones et al., 2002). The 17 antimicrobials were as follows: chloramphenicol (C, $30 \mu \mathrm{g}$ ), ciprofloxacin (CIP, $5 \mu \mathrm{g}$ ), clindamycin (DA, $2 \mu \mathrm{g}$ ), erythromycin (E, $15 \mu \mathrm{g}$ ), fusidic acid (FA, $10 \mu \mathrm{g})$, gentamicin $(\mathrm{CN}, 10 \mu \mathrm{g})$, kanamycin $(\mathrm{K}, 30$ $\mu \mathrm{g}$ ), linezolid (LNZ, $10 \mu \mathrm{g}$ ), penicillin ( $\mathrm{P}, 10 \mu \mathrm{g}$ ), quinupristin-dalfopristin (SYN, $15 \mu \mathrm{g}$ ), rifampin (RA, $5 \mu \mathrm{g}$ ), streptomycin (S, $10 \mu \mathrm{g})$, sulphamethoxazole-trimethoprim (STX, $25 \mu \mathrm{g}$ ), tetracycline (TE, $30 \mu \mathrm{g}$ ), tiamulin (TIA, $30 \mu \mathrm{g}$ ), tigecycline (TGC, $15 \mu \mathrm{g}$ ) and tobramycin (TOB, $10 \mu \mathrm{g}$ ). Antibiotics were used as indicators of possible acquired resistance and not for clinical purposes. Genetic determinants of tetracycline resistance tet(K), tet( $M)$ were amplified with primers tetK-1/tetK-2, and tetM-1/tetM-2, respectively (Strommenger et al., 2003), while tet(L) was detected using primers tet(L)-2-1 and tet(L)-2-2, described by Aarestrup et al. (2000). Aminoglycoside-modifying enzyme genes aacA-aphD, aphA3 and aadD were detected by a multiplex PCR (Schmitz et al., 1999).

\section{RESULTS}

Between 2003 and 2018, 27 MRSA strains originating from 10 dairy farms were deposited in the culture collection of the VDD. From these, 12 were recovered from one farm and were partly characterised by Juhász-Kaszanyitzky et al. (2007). The

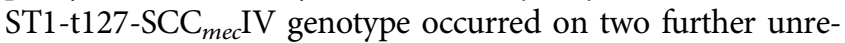
lated farms (one and seven isolates, respectively), also causing subclinical mastitis outbreaks. Variable genotypes were identified sporadically from other farms: ST22-t032-SCC $m$ ${ }_{c} \mathrm{IV}(n=3)$ from three farms; a newly described double locus variant of ST97, ST5982-t458-SCC ${ }_{m e c} \mathrm{IV}(n=2)$ from two farms; and the ST398-t011-SCC ${ }_{m e c} \mathrm{IV}(n=1)$ and V $(n=1)$ from two respective farms. The prospective screening resulted in 626 individual SA isolates originating from 42 dairy farms (1-117 isolates per farm). Among these, only four MRSA strains (0.48\%) were identified. Most strains (591/626) arrived from farms with five or more SA isolates during the survey period (20/42 farms). The four MRSA strains were recovered from three farms $(7.14 \%)$ and all of them belonged to the clonal complex 398. Among these, spa-type t19251 is described here for the first time. All investigated MRSA strains proved to be PVL negative.

All but two of the 14 representative isolates were resistant to at least four antimicrobial classes, among which resistance to tetracycline (11/14), clindamycin (10/14), gentamycin (10/14), ciprofloxacin (9/14) and streptomycin $(8 / 14)$ were the most prevalent. All investigated isolates were susceptible to quinupristin-dalfopristin and tigecycline, and only sporadic resistance $(n=1)$ could be observed in the 
case of the following compounds: chloramphenicol, fusidic acid, linezolid and rifampin. The molecular investigation of the tetracycline and aminoglycoside resistance genes corresponded well with the phenotype of the strains: at least one gene encoding the respective resistance could be detected. Further details of the results are summarised in Table 1.

\section{DISCUSSION}

According to the investigation of 626 individual isolates originating from 42 dairy holdings, the occurrence of methicillin-resistant strains seems to be rare among SA isolates from bovine milk. The results suggest prevalence rates similar to those found in the last surveys conducted in Hungary. Between 2002 and 2003 Kaszanyitzky et al. (2004) detected only five MRSA strains among 867 SA isolates originating from bovine milk $(0.58 \%)$. In another study, no MRSA could be isolated from bulk tank milk samples of 20 dairy farms (Peles et al., 2007).
As a comparison, the 42 holdings in our survey represent approximately $7-8 \%$ of the total number of performancetested dairy holdings, according to the register of the LPT Ltd. The number varied between 519 and 527 during the survey period (data available at https://www.atkft.hu/ partnertajekoztato-hirlevel/). As no further statistics could be performed on our data, it can only be assumed that the burden presented by MRSA is still not significant in the Hungarian dairy sector. This tendency is in accordance with data from other European countries, where the overall prevalence of MRSA-positive dairy herds varies between 0 and 10\% (Schnitt and Tenhagen, 2019). Meanwhile a large-scale meta-analysis of the timeframe 2007-2016 also implies a low worldwide prevalence of 2.2\% (Ou et al., 2017). The percentage of MRSA within SA isolates of milk is also comparable with the observations of others (Luini et al., 2015).

In this study, most of the isolates (20/31) belonged to the ST1-t127 genotype. This genotype has emerged as a human community associated MRSA in the USA carrying the

Table 1. Methicillin-resistant Staphylococcus aureus strains of bovine milk origin

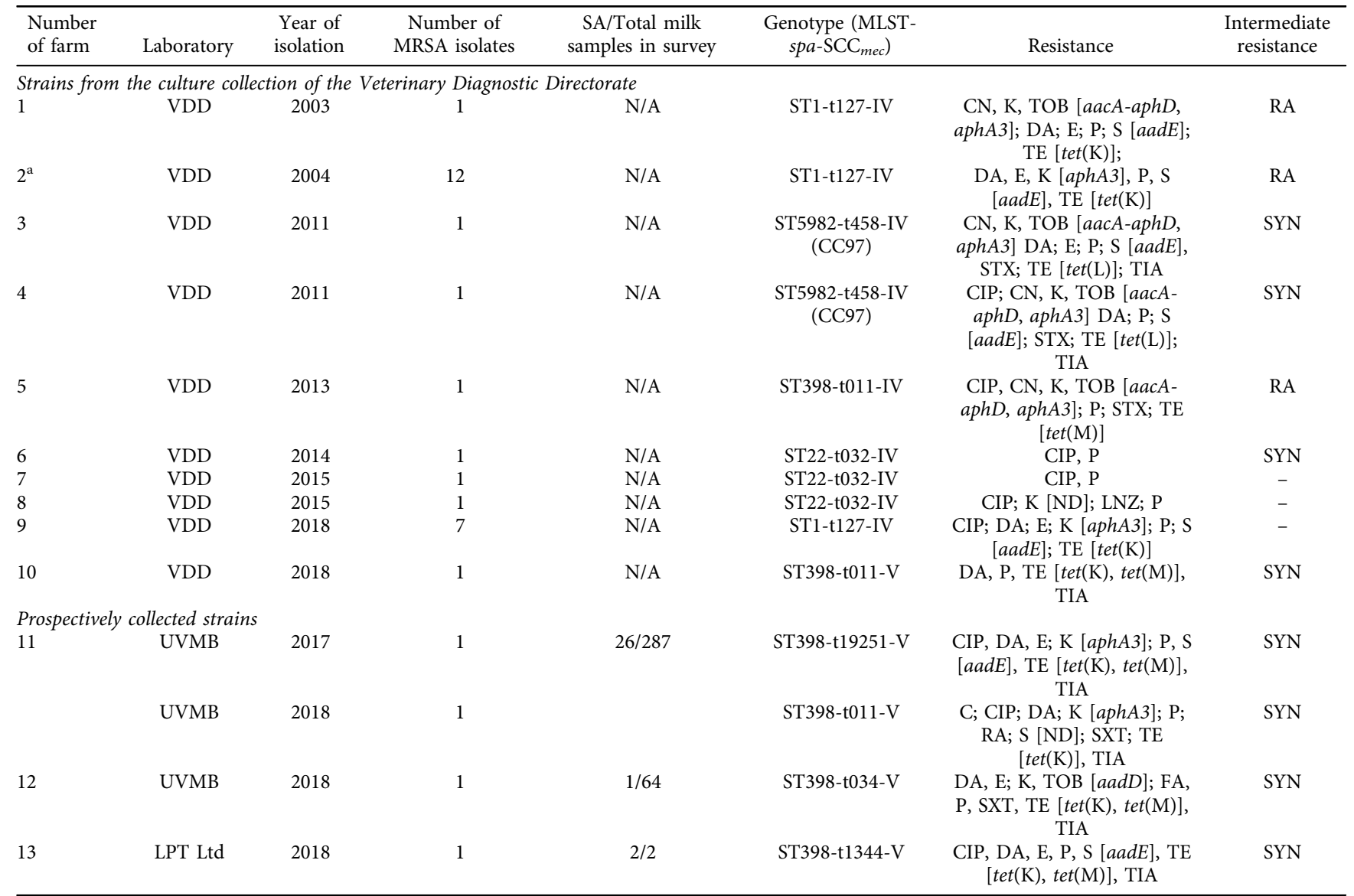

C, chloramphenicol; CN, gentamicin; CIP, ciprofloxacin; DA, clindamycin; E, erythromycin; FA, fusidic acid; K, kanamycin; LNZ, linezolid; P, penicillin; SYN, quinupristin-dalfopristin; RA, rifampicin; S, streptomycin; SXT, trimethoprim and sulphamethoxazole; TE, tetracycline; TIA, tiamulin, TGC, tigecycline; TOB, tobramycin; aacA-aphD, bifunctional aminoglycoside acetyltransferase and phosphotransferase (AAC/APH) gene; aphA3, aminoglycoside O-phosphotransferase APH( $\left.3^{\prime}\right)$-IIIa gene; aadD, aminoglycoside adenyltransferase AadD gene; aadE, aminoglycoside adenyltransferase AadE gene; tet $(\mathrm{K})$, tetracycline resistance protein TetK gene; tet $(\mathrm{M})$, tetracycline resistance protein TetM gene; MLST, multilocus sequence type; SA, Staphylococcus aureus; spa, Staphylococcus aureus protein A sequence type, SCC $_{\text {mec }}$, Staphylococcus cassette chromosome mec type; N/A, not applicable.

" The genotype of the strains originating from Farm No. 2 had previously been investigated by Juhász-Kaszanyitzky et al. (2007). 
potent human virulence factor (the PVL gene); it has since been reported worldwide with variants being either PVL positive or PVL negative. The PVL-negative variant of the lineage from animals and a dairy worker was first described in Hungary in the early 2000s by Juhász-Kaszanyitzky et al. (2007), who determined the genotype but did not investigate the resistance profile of the isolates. More recently, the lineage has become widely distributed in Italy and is occasionally reported from other countries of Southeast Europe, both from humans and animals (Cuny et al., 2015). In dairy herds, ST1-t127 MRSA is frequently recovered from subclinical and clinical mastitis cases. Phylogenetic studies suggest a potential human origin of the cow-related strains, while the clonal lineage retains specific virulence and immunomodulatory genes, and thus is able to colonise the human host (Alba et al., 2015).

The second most frequent clonal lineage in this study was clonal complex (CC) 398. This initially swine-related MRSA genotype has also appeared and become widely distributed in most domesticated and wild animal species and also in humans, due to its low host specificity (Cuny et al., 2015). It may cause subclinical and eventually clinical mastitis outbreaks in cattle herds (Vanderhaeghen et al., 2010; Spohr et al., 2011), yet the pathogenic ability and role of CC398 in dairy production still needs further investigation. Regardless of their origin and virulence genes, all CC398 strains can colonise the human host (Cuny et al., 2015).

Three strains shared the same ST22-t032 genotype, which is identical to the human epidemic UK-EMRSA-15 clonal lineage. The lineage was proven to colonise horses and companion animals (Walther et al., 2012; Vincze et al., 2014). MRSA CC22 has also been implicated in bovine mastitis and simultaneous human nasal carriage on one farm in Italy. The authors concluded that humanosis was the only possible way of introducing the pathogen into the closed dairy herd (Magro et al., 2018). The newly described ST5982-t458 belonged to CC97, which was originally described in ruminants, either as methicillin-sensitive SA or MRSA, and accounted as one of the most prevalent genotypes. Some sub-lineages of the clonal complex have become pandemic within the human population in recent years, and could already be isolated in countries of four continents (Spoor et al., 2013).

In the case of MRSA, antibiotic pressure is a major driver for selection. All but two strains were resistant to at least three or more classes of antimicrobial agents, fulfilling the term of multiresistance. The antibiogram also helps to allocate the recovered isolates to the most probable host group. For instance, tetracycline resistance is a hallmark of more LA-MRSA lineages, due to the long-term and widescale usage of the compound in farm animal husbandry (Price et al., 2012; Ye et al., 2016; Hau et al., 2018). Only three strains of ST22-t032 showed tetracycline susceptibility, further supporting the possible human origin of these latter isolates.

Resistance to ciprofloxacin, clindamycin, kanamycin and streptomycin was also widespread among the investigated isolates. These compounds are categorised as critically important or highly important antibiotics for human medicine, according to the World Health Organization (2018). The detected genes coding for kanamycin, gentamicin, tobramycin, tetracycline and streptomycin resistance are encoded on mobile genetic elements (i.e., plasmids and transposons), allowing horizontal gene flow among strains or even species of staphylococci in different hosts. This highlights the possibility of a mutual exchange of resistance determinants between staphylococci of human and animal origin (Wendlandt et al., 2013).

In conclusion, the occurrence and significance of MRSA of dairy origin seems to be unchanged in the past decade in Hungary. All investigated genetic lineages can colonise the human host, however mutual exchange between humans and animals may also take place, especially in humans who are in occupational contact with livestock (Cuny et al., 2015). The latest research suggests the re-adaptation of CC398 MRSA from swine to humans by changing its mobile genetic elements. The loss of certain livestock-associated resistance determinants [e.g. $\operatorname{erm}(\mathrm{B}), \ln u(\mathrm{~B})$ and $\operatorname{tet}(\mathrm{K})]$ or the gain of the human-associated, prophage-located virulence genes, the immune evasion-cluster (IEC), are part of a process to better fit the new host (Sieber et al., 2019). Such rapid evolutionary scenes in other fields of animal husbandry call for periodic revision of the role and distribution of the pathogen in the Hungarian dairy sector.

\section{ACKNOWLEDGEMENTS}

The authors thank Ágnes Erös and Bernadett Kelemen for their technical assistance and Dr Attila Monostori, LPT Ltd., for kindly providing access to the strains and related data. The project was supported by the European Union and cofinanced by the European Social Fund (grant agreement no. EFOP-3.6.3-VEKOP-16-2017-00005, project title: 'Strengthening the scientific replacement by supporting the academic workshops and programs of students, developing a mentoring process') through a grant to EA.

\section{REFERENCES}

Aarestrup, F. M., Agerso, Y., Gerner-Smidt, P., Madsen, M. and Jensen, L. B. (2000): Comparison of antimicrobial resistance phenotypes and resistance genes in Enterococcus faecalis and Enterococcus faecium from humans in the community, broilers, and pigs in Denmark. Diagn. Microbiol. Infect. Dis. 37, 127137.

Alba, P., Feltrin, F., Cordaro, G., Porrero, M. C., Kraushaar, B., Argudín, M. A., Nykäsenoja, S., Monaco, M., Stegger, M., Aarestrup, F. M., Butaye, P., Franco, A. and Battisti, A. (2015): Livestock-associated methicillin resistant and methicillin susceptible Staphylococcus aureus sequence type (CC) 1 in European farmed animals: High genetic relatedness of isolates from Italian cattle herds and humans. PLoS One 10, https://doi.org/ 10.1371/journal.pone.0137143. 
Cortimiglia, C., Luini, M., Bianchini, V., Marzagalli, L., Vezzoli, F., Avisani, D., Bertoletti, M., Ianzano, A., Franco, A. and Battisti, A. (2016): Prevalence of Staphylococcus aureus and of methicillin-resistant $S$. aureus clonal complexes in bulk tank milk from dairy cattle herds in Lombardy Region (Northern Italy). Epidemiol. Infect. 144, 3046-3051.

Cuny, C., Wieler, L. and Witte, W. (2015): Livestock-associated MRSA: The impact on humans. Antibiotics 4, 521-543.

Devriese, L. A., Van Damme, L. R. and Fameree, L. (1972): Methicillin (cloxacillin)-resistant Staphylococcus aureus strains isolated from bovine mastitis cases. Zbl. Vet. Med. B 19, 598605.

Enright, M. C., Day, N. P. J., Davies, C. E., Peacock, S. J. and Spratt, B. G. (2000): Multilocus sequence typing for characterization of methicillin-resistant and methicillin-susceptible clones of Staphylococcus aureus. J. Clin. Microbiol. 38, 1008-1015.

European Committee on Antimicrobial Susceptibility Testing (2019): Breakpoint tables for interpretation of MICs and zone diameters. Version 9.0. Available at http://eucast.org.

European Food Safety Authority (2009): Analysis of the baseline survey on the prevalence of methicillin-resistant Staphylococcus aureus (MRSA) in holdings with breeding pigs, in the EU 2008 - Part A: MRSA prevalence estimates. EFSA J. 7, 1376.

Fitzgerald, J. R. (2012): Livestock-associated Staphylococcus aureus: Origin, evolution and public health threat. Trends Microbiol. 20, 192-198.

Harmsen, D., Claus, H., Witte, W., Rothgänger, J., Claus, H., Turnwald, D. and Vogel, U. (2003): Typing of methicillinresistant Staphylococcus aureus in a university hospital setting by using novel software for spa repeat determination and database management. J. Clin. Microbiol. 41, 5442-5448.

Hau, S. J., Haan, J. S., Davies, P. R., Frana, T. and Nicholson, T. L. (2018): Antimicrobial resistance distribution differs among methicillin resistant Staphylococcus aureus sequence type (ST) 5 isolates from health care and agricultural sources. Front. Microbiol. 9, https://doi.org/10.3389/fmicb.2018.02102.

Jones, R. N., Pfaller, M. A., Rhomberg P. R. and Walter, D. H. (2002): Tiamulin activity against fastidious and nonfastidious veterinary and human bacterial isolates: Initial development of in-vitro susceptibility test methods. J. Clin. Microbiol. 40, 461465.

Juhász-Kaszanyitzky, É., Jánosi, S., Somogyi, P., Dán, Á., van der Graaf-van Bloois, L., van Duijkeren, E. and Wagenaar, J. A. (2007): MRSA transmission between cows and humans. Emerg. Infect. Dis. 13, 630-632.

Kaszanyitzky, É. J., Egyed, Zs., Jánosi, Sz., Keserü, J., Gál, Zs., Szabó, I., Veres, Z. and Somogyi, P. (2004): Staphylococci isolated from animals and food with phenotypically reduced susceptibility to beta-lactamase-resistant beta-lactam antibiotics. Acta Vet. Hung. 52, 7-17.

Klare, I., Konstabel, C., Werner, G., Huys, G., Vankerckhoven, V., Gunnar Kahlmeter, G., Hildebrandt, B., Müller-Bertling, S., Witte, W. and Goossens, H. (2007): Antimicrobial susceptibilities of Lactobacillus, Pediococcus and Lactococcus human isolates and cultures intended for probiotic or nutritional use. J. Antimicrob. Chemother. 59, 900-912.

Kondo, Y., Ito, T., Ma, X. X., Watanabe, S., Kreiswirth, B. N., Etienne, J. and Hiramatsu, K. (2007): Combination of multiplex
PCRs for staphylococcal cassette chromosome mec type assignment: Rapid identification system for mec, ccr, and major differences in junkyard regions. Antimicrob. Agents Chemother. 51, 264-274.

Luini, M., Cremonesi, P., Magro, G., Bianchini, V., Minozzi, G., Castiglioni, B. and Piccinini, R. (2015): Methicillin-resistant Staphylococcus aureus (MRSA) is associated with low withinherd prevalence of intra-mammary infections in dairy cows: Genotyping of isolates. Vet. Microbiol. 178, 270-274.

Magro, G., Rebolini, M., Beretta, D. and Piccinini, R. (2018): Methicillin-resistant Staphylococcus aureus CC22-MRSA-IV as an agent of dairy cow intramammary infections. Vet. Microbiol. 227, 29-33.

Matuschek, E., Brown, D. F. and Kahlmeter, G. (2014): Development of the EUCAST disk diffusion antimicrobial susceptibility testing method and its implementation in routine microbiology laboratories. Clin. Microbiol. Infect. 20, 255-266.

Ou, Q., Zhou, J., Lin, D., Bai, C., Zhang, T., Lin, J., Zheng, H., Wang, X., Ye, J., Ye, X. and Yao, Z. (2017): A large metaanalysis of the global prevalence rates of $S$. aureus and MRSA contamination of milk. Crit. Rev. Food Sci. Nutr. 58, 22132228.

Parisi, A., Caruso, M., Normanno, G., Latorre, L., Sottili, R., Miccolupo, A., Fraccalvieri, R. and Santagada, G. (2016): Prevalence, antimicrobial susceptibility and molecular typing of methicillin-resistant Staphylococcus aureus (MRSA) in bulk tank milk from southern Italy. Food Microbiol. 58, 36-42.

Peles, F., Wagner, M., Varga, L., Hein, I., Rieck, P., Gutser, K., Keresztúri, P., Kardos, G., Turcsányi, I., Béri, B. and Szabó, A. (2007): Characterization of Staphylococcus aureus strains isolated from bovine milk in Hungary. Int. J. Food Microbiol. 118, 186-193.

Price, L. B., Stegger, M., Hasman, H., Aziz, M., Larsen, J., Andersen, P. S., Pearson, T., Waters, A. E., Foster, J. T., Schupp, J., Gillece, J., Driebe, E., Liu, C. M., Springer, B., Zdovc, I., Battisti, A., Franco, A., Żmudzki, J., Schwarz, S., Butaye, P., Jouy, E., Pomba, C., Porrero, M. C., Ruimy, R., Smith, T. C., Robinson, D. A., Weese, J. S., Arriola, C. S., Yu, F., Laurent, F., Keim, P., Skov, R. and Aarestrup, F. M. (2012): Staphylococcus aureus CC398: Host adaptation and emergence of methicillin resistance in livestock. mBio. 3, https://doi.org/10.1128/mBio. 00305-11.

Schijffelen, M. J., Boel, C. H., van Strijp, J. A. and Fluit, A. C. (2010): Whole genome analysis of a livestock-associated methicillin-resistant Staphylococcus aureus ST398 isolate from a case of human endocarditis. BMC Genom. 11, 376.

Schmitz, F.-J., Fluit, A. C., Gondolf, M., Beyrau, R., Lindenlauf, E., Verhoef, J., Heinz, H.-P. and Jones, M. E. (1999): The prevalence of aminoglycoside resistance and corresponding resistance genes in clinical isolates of staphylococci from 19 European hospitals. J. Antimicrob. Chemother. 43, 253-259.

Schnitt, A. and Tenhagen, B.-A. (2019): Risk factors for the occurrence of methicillin-resistant Staphylococcus aureus in dairy herds: An update. Foodborne Pathog. Dis. (ahead of print) https://doi.org/10.1089/fpd.2019.2638.

Sieber, R. N., Larsen, A. R., Urth, T. R., Iversen, S., Møller, C. H., Skov, R. L., Larsen, J. and Stegger, M. (2019): Genome investigations show host adaptation and transmission of LA- 
MRSA CC398 from pigs into Danish healthcare institutions. Sci. Rep. 9, 1-10.

Spohr, M., Rau, J., Friedrich, A., Klittich, G., Fetsch, A., Guerra, B., Hammerl, J. A. and Tenhagen, B.-A. (2011): Methicillin-resistant Staphylococcus aureus (MRSA) in three dairy herds in southwest Germany. Zoonoses Public Health 58, 252-261.

Spoor, L. E., McAdam, P. R., Weinert, L. A., Rambaut, A., Hasman, H., Aarestrup, F. M., Kearns, A. M., Larsen, A. R., Skov, R. L. and Fitzgerald, J. R. (2013): Livestock origin for a human pandemic clone of community-associated methicillin-resistant Staphylococcus aureus. mBio. 4, https://doi.org/10.1128/mBio.00356-13.

Stegger, M., Andersen, P. S., Kearns, A., Pichon, B., Holmes, M. A., Edwards, G., Laurent, F., Teale, C., Skov, R. and Larsen, A. R. (2012): Rapid detection, differentiation and typing of methicillin-resistant Staphylococcus aureus harbouring either mecA or the new mecA homologue mec $A_{L G A 251}$. Clin. Microbiol. Infect. 18, 395-400.

Strommenger, B., Kettlitz, C., Werner, G. and Witte, W. (2003): Multiplex PCR assay for simultaneous detection of nine clinically relevant antibiotic resistance genes in Staphylococcus aureus. J. Clin. Microbiol. 41, 4089-4094.

Tenhagen, B.-A., Vossenkuhl, B., Käsbohrer, A., Alt, K., Kraushaar, B., Guerra, B., Schroeter, A. and Fetsch, A. (2014): Methicillinresistant Staphylococcus aureus in cattle food chains - Prevalence, diversity, and antimicrobial resistance in Germany. J. Anim. Sci. 92, 2741-2751.

Vanderhaeghen, W., Cerpentier, T., Adriaensen, C., Vicca, J., Hermans, K. and Butaye, P., (2010): Methicillin-resistant Staphylococcus aureus (MRSA) ST398 associated with clinical and subclinical mastitis in Belgian cows. Vet. Microbiol. 144, 166-171. van Duijkeren, E., Hengeveld, P. D., Albers, M., Pluister, G., Jacobs, P., Heres, L. and van de Giessen, A. W. (2014): Prevalence of methicillin-resistant Staphylococcus aureus carrying mecA or mecC in dairy cattle. Vet. Microbiol. 171, 364-367.

Vincze, S., Stamm, I., Kopp, P. A., Hermes, J., Adlhoch, C., Semmler, T., Wieler, L. H., Lübke-Becker, A. and Walther, B. (2014): Alarming proportions of methicillin-resistant Staphylococcus aureus (MRSA) in wound samples from companion animals, Germany 2010-2012. PLoS One 9, https://doi.org/10. 1371/journal.pone.0085656.

Walther, B., Hermes, J., Cuny, C., Wieler, L. H., Vincze, S., Abou Elnaga, Y., Stamm, I., Kopp, P. A., Kohn, B., Witte, W., Jansen, A., Conraths, F. J., Semmler, T., Eckmanns, T. and LübkeBecker, A. (2012): Sharing more than friendship - Nasal colonization with coagulase-positive staphylococci (CPS) and co-habitation aspects of dogs and their owners. PLoS One 7, https://doi.org/10.1371/journal.pone.0035197.

Wendlandt, S., Feßler, A. T., Monecke, S., Ehricht, R., Schwarz, S. and Kadlec, K. (2013): The diversity of antimicrobial resistance genes among staphylococci of animal origin. Int. J. Med. Microbiol. 303, 338-349.

World Health Organization (2018): Critically Important Antimicrobials for Human Medicine. World Health Organization, Geneva, 6th revision. pp. 27-40. https://apps.who.int/iris/ bitstream/handle/10665/312266/9789241515528-eng.pdf?ua =1.

Ye, X., Wang, X., Fan, Y., Peng, Y., Li, L., Li, S., Huang, J., Yao, Z. and Chen, S. (2016): Genotypic and phenotypic markers of livestock-associated methicillin-resistant Staphylococcus aureus CC9 in humans. Appl. Environ. Microbiol. 82, 38923899.

Open Access. This is an open-access article distributed under the terms of the Creative Commons Attribution 4.0 International License (https://creativecommons.org/ licenses/by/4.0/), which permits unrestricted use, distribution, and reproduction in any medium, provided the original author and source are credited, a link to the CC License is provided, and changes - if any - are indicated. (SID_1) 